\title{
Mouse fetal antigen 1 (mFA1), the circulating gene product of $m d l k$, pref-1 and SCP-1: isolation, characterization and biology
}

\author{
E. Bachmann ${ }^{1}$, T. N. Krogh ${ }^{2}$, P. Højrup ${ }^{2}$, K. Skjødt $^{1}$ and B. Teisner ${ }^{1 *}$ \\ ${ }^{1}$ Department of Medical Microbiology and ${ }^{2}$ Institute of Molecular Biology, University of Odense, \\ Denmark
}

\begin{abstract}
The mouse homologue to human fetal antigen 1 (hFA1) was purified from mouse amniotic fluid by cation exchange chromatography and immunospecific affinity chromatography. Mouse FA1 (mFA1) is a single chain glycoprotein with an $M_{\mathrm{r}}$ of $42-50 \mathrm{kDa}$ (SDS-PAGE). The N-terminal amino acid sequence (39 residues) revealed $74 \%$ identity to $\mathrm{hFAI}$ and $100 \%$ identity to the translated cDNAs referred to as mouse $d l k$, pref- 1 and SCP-1. mFA1 is the secreted processed molecule encoded by the mRNA defined by these identical mouse cDNAs. Monospecific rabbit anti-mFAI antibodies, purified by ammonium sulfate precipitation and immunospecific affinity chromatography, were used for immunohistochemical and quantitative ELISA techniques. The indirect immunoperoxidase technique demonstrated mFAI within the endocrine structures of adult mouse pancreas, whereas the exocrine tissue remained unstained. FAI-positive staining was also seen in the pituitary gland and the mouse adrenal gland. The concentration of $\mathrm{mFAI}$ in a pool of amniotic fluid was assessed at $25 \mu \mathrm{g} \mathrm{ml}^{-1}$ and the serum concentration in normal nonpregnant adult mice $(n=28)$ was $11.3 \pm 5.0 \mathrm{ng} \mathrm{ml}^{-1}(2 \mathrm{SD})$. During pregnancy the concentration of mFAI in maternal serum increased above the nonpregnant reference value at midpregnancy, reaching a maximum concentration $\left(>0.35 \mu \mathrm{g} \mathrm{ml}^{-1}\right.$ ) 2 days prepartum. The maternal serum concentration was positively correlated with the number of fetuses. After delivery the rate of disappearance of mFAI in maternal serum was very fast with a $t_{1 / 2}<1 \mathrm{~h}$. The concentration of mFAI in newborn mice was about $15 \mu \mathrm{g} \mathrm{ml}{ }^{-1}$ and did not reach normal adult values until the age of $>50$ days.
\end{abstract}

\section{Introduction}

Human fetal antigen I (hFAI) was originally isolated from second trimester amniotic fluid (Fay et al., 1988). The fetal origin of hFAI was suggested after observations on the quantitative distribution in fetal and maternal compartments, together with immunohistochemical analysis (Fay et al., 1988; Tornehave et al., 1989). Radioimmunoassay revealed hFA1 concentrations in normal adult serum 1000 times lower than that seen in amniotic fluid (Jensen, 1992).

Immunohistochemical studies have demonstrated human FAI in the fetal hepatocytes, fetal adrenal cortex, all glandular cells of the early pancreas primordium and around the blood islands of the yolk sac (Tornehave et al., 1989, 1993; Palomino et al., 1992; Jensen $e$ al., 1993, 1994). In adult tissue, however, the liver is FAI negative, whereas FAI in the pancreas is restricted to the insulin producing $\beta$-cells, and in the adult adrenal the most pronounced staining is seen in the cortex (Jensen et al., 1993, 1994).

The primary structure of hFA1 (Jensen et al., 1993, 1994) demonstrates the presence of six epidermal growth factor

*Correspondence.

Received 12 January 1996.
(EGF)-like repeats, categorizing this single chain molecule of $32-38 \mathrm{kDa}$ as a new circulating member of the EGF superfamily. There is a striking similarity between $\mathrm{hFAI}$ and the Delta and Notch proteins in Drosophila, and to the mammalian homologues of these proteins (Artavanis-Tsakonas et al., 1995) which are involved in the development of the embryonic ectoderm into epidermal and neural structures. Comparison of the hFAI sequence to the published translated cDNA sequences reveals that hFA1 is the processed circulating form of the gene product of human $d l k$ (Delta like), which may be a membrane protein synthesized in neuroendocrine tumours (Laborda et al., 1993). Human dlk cDNA is identical to the cDNA $p G 2$ described as 'adrenal specific' when the latter sequence is corrected for sequence errors (Jensen et al., 1993, 1994). Moreover, hFAl has been demonstrated in neuroendocrine tumours of the lung (Jensen et al., 1994) and in the somatroph cells of the pituitary gland (Larsen et al., 1996). The mouse homologue to human dlk (mdlk) is identical to the cDNA from a mouse stromal cell line referred to as SCP-1 (Maruyama et al., 1993) and a cDNA described as pref-1 (Smas and Sul, 1993), which may be involved in the differentiation of 3T3-L1 fibroblasts to adipocytes. The gene product of pref-1 may be a membrane protein and no secreted form has been described. 
The present study describes the isolation and characterization of circulating mouse FA1 (mFA1), production of antibodies, immunohistochemistry, quantitative methods and biology of $\mathrm{mFA1}$, with the primary aim to establish a laboratory animal model for further analysis of the biological significance of FA1.

\section{Materials and Methods}

\section{Antigen source}

Mouse FAI was purified from amniotic fluid obtained at days 16-19 of mouse pregnancy.

\section{Physicochemical purification of $m F A 1$}

Amniotic fluid was dialysed against $50 \mathrm{mmol}$ citratephosphate buffer $1^{-1}, \mathrm{pH} 4.5$, centrifuged at $40000 \mathrm{~g}$ for $30 \mathrm{~min}$ at $4^{\circ} \mathrm{C}$ and the supernatant was applied to a CM-Sepharose FF column (Pharmacia, Uppsala) equilibrated with citrate-phosphate buffer, $\mathrm{pH}$ 4.5. The column was washed with the citrate-phosphate buffer and the peak effluent was

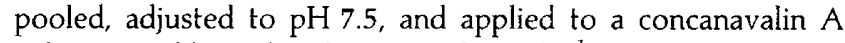
column equilibrated with $20 \mathrm{mmol}$ Tris $1^{-1}$ containing $1 \mathrm{mmol}$ $\mathrm{MgCl}_{2} \mathrm{I}^{-1}, 1 \mathrm{mmol} \mathrm{CaCl} \mathrm{I}^{-1}$ and $0.6 \mathrm{~mol} \mathrm{NaCl}^{-1}$. After washing, the column was eluted with $10 \%(\mathrm{w} / \mathrm{v}) \alpha$-Dmannoside and the eluted peak fractions were pooled and dialysed against $10 \mathrm{mmol}$ Tris- $\mathrm{HCl} 1^{-1}, \mathrm{pH} 8.5$ and applied to a Mono Q, H5/5 column, pre-equilibrated with the Tris buffer. The column was washed with ten bed volumes of Tris buffer and eluted with $10 \mathrm{mmol}$ Tris $-\mathrm{HCl} \mathrm{I}^{-1}, \mathrm{pH} 8.5$, $1 \mathrm{~mol} \mathrm{NaCl}{ }^{-1}$.

\section{Immunospecific purification of $m F A 1$}

The first affinity chromatography matrix was based on direct coupling of dissociated immune complexes to $\mathrm{CNBr}$-activated Sepharose $4 \mathrm{~B}$ (Pharmacia) essentially as described by Folkersen et al. (1980). The immune complexes were formed by mixing $3.5 \mathrm{ml}$ mouse amniotic fluid with $10 \mathrm{ml}$ antiserum against mFA1 purified based on physicochemical properties, and absorbed to monospecificity with normal mouse serum, followed by incubation at $37^{\circ} \mathrm{C}$ for $1 \mathrm{~h}$ and $4^{\circ} \mathrm{C}$ overnight. The immune complexes were isolated, washed, dissociated and coupled to CNBr-activated Sepharose as described by Jensen et al. (1993).

The matrix was packed on a column and connected to the fast performance liquid chromatography (FPLC) system (Pharmacia). Before application of sample, the column was washed with PBS $+1 \mathrm{~mol} \mathrm{NaCl} l^{-1}$ (washing buffer), eluted with $0.5 \%(\mathrm{w} / \mathrm{v})$ citric acid, $\mathrm{pH} 2.3$ and re-equilibrated with washing buffer.

After application of amniotic fluid, the column washed to baseline (Absorbance $280 \mathrm{~nm}$ ) and $\mathrm{mFA1}$ was eluted with citric acid. The eluted mFAI was dialysed against PBS and subsequently used for immunization of new rabbits and for coupling to $\mathrm{CNBr}$-activated Sepharose.

The next affinity matrix was produced by coupling of affinity purified rabbit anti-mFAI Ig (see below) to
CNBr-activated Sepharose according to the manufacturer's recommendation. This column was run as described above and the eluate used for antibody production and analysis of the primary structure of FA1.

\section{Production and preparation of rabbit anti-mFA1 antibodies}

Purified mFAI $(30 \mu \mathrm{g})$ was mixed with an equal volume of Freund's incomplete adjuvant and injected into rabbits at intervals of 28 days. The resulting antiserum was absorbed to monospecificity with serum from adult mice and defined as monospecific when one immunoprecipitate was seen using amniotic fluid as antigen and no precipitate was seen using adult mouse serum as antigen in crossed immunoelectrophoresis $\left(50 \mu \mathrm{l}\right.$ antiserum $\mathrm{cm}^{-2}$ agarose; $13 \mu \mathrm{l}$ undiluted antigen samples).

The monospecific rabbit anti-mFAI antiserum was prepared in two ways: (1) For immunohistochemistry and electroimmunoassay, the IgG fraction of the antiserum was isolated by ammonium sulfate precipitation (Harboe and Ingild, 1973) and dissolved in PBS. (2) For the affinity purification of rabbit anti-mFA1 immunoglobulin, an affinity matrix was coupled with purified $m F A 1$. The purification procedure was identical to that described for immunospecific purification of MFA1.

\section{Electroimmunoassays}

Crossed immunoelectrophoresis and rocket immunoelectrophoresis were performed essentially as described by Jensen et al. (1993) and Fay et al. (1988). Rocket immunoelectrophoresis was used to quantify mFAI during purification using a twofold dilution series of amniotic fluid as calibrator.

\section{SDS-PAGE}

SDS-PAGE was carried out under reducing conditions on precast $8-20 \%$ polyacrylamide gradient gels on a Phast system (Pharmacia) followed by silverstaining according to the manufacturer's recommendations.

\section{$N$-terminal amino acid sequencing}

N-terminal sequencing was performed as described by Jensen et al. (1993). Before sequencing, mFAI was reduced and alkylated using 4-vinylpyridine and purified on a Vydac $\mathrm{C} 4$ reversed-phased column $(4 \mathrm{~mm} \times 250 \mathrm{~mm})$ running a gradient of $10-60 \% 2$-propanol in $0.1 \%(\mathrm{v} / \mathrm{v})$ trifluoroacetic acid (TFA) water. The N-terminal sequence was determined on an automated Knauer 910 protein sequencer with identification of phenylthiohydantion derivates by online reversed-phase high performance liquid chromatography (HPLC).

\section{Immunohistochemistry}

Indirect immunoperoxidase staining was performed on $2-4 \mu \mathrm{m} 4 \%(\mathrm{w} / \mathrm{v})$ formalin fixed air-dried sections of pancreas from adult mice, essentially as described by Jensen et al. (1993). The sections were incubated with ammonium sulfate precipitated purified rabbit anti-mFA1 $\operatorname{IgG}$, diluted $1: 300$ in PBS 


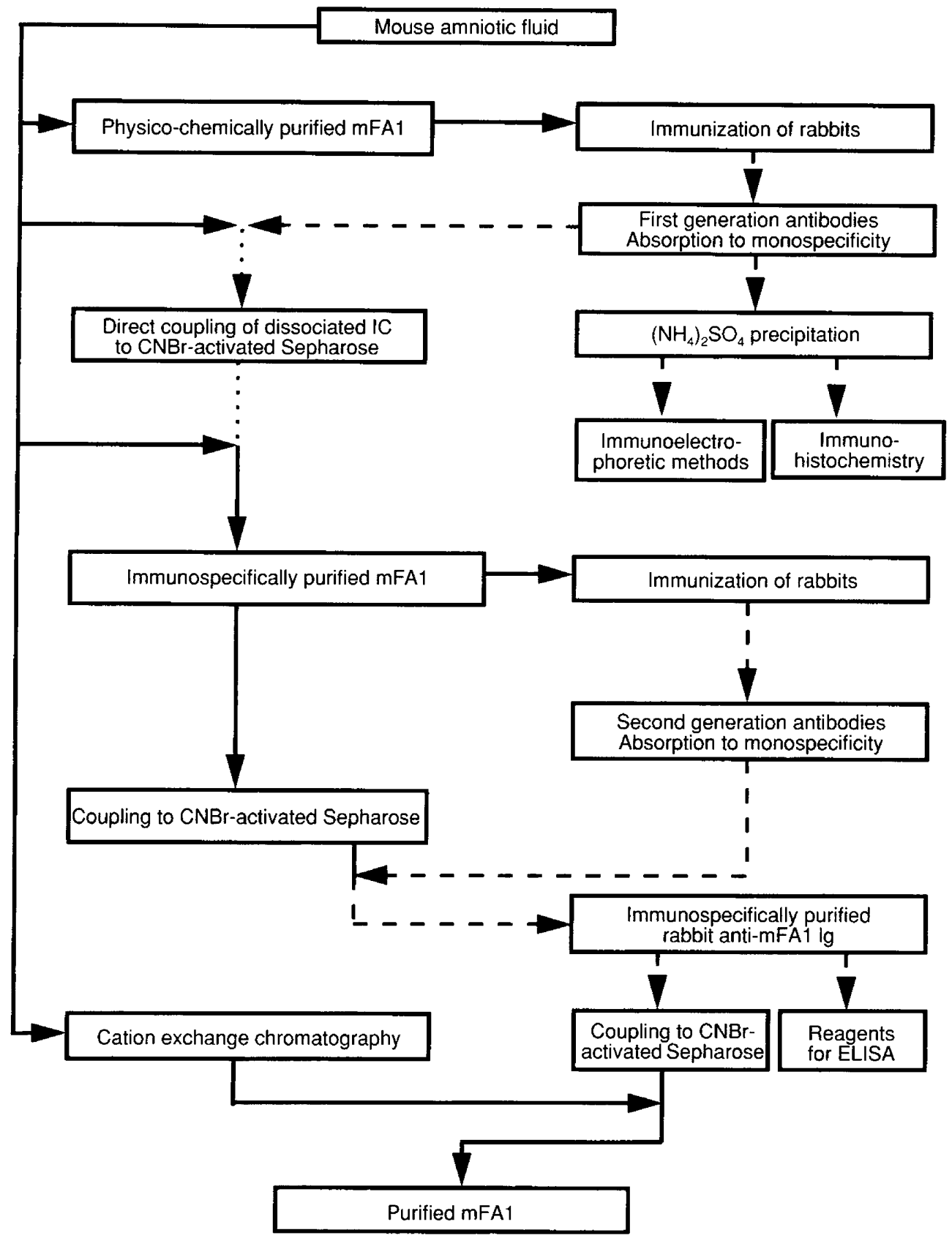

Fig. 1. Flowchart showing the sequence in preparation, purification and applications of mouse fetal antigen $1(\mathrm{mFA1})(\longrightarrow)$ and rabbit antibodies against mFA1 $(---)$. IC: immune complexes.

containing $1 \%(\mathrm{w} / \mathrm{v})$ BSA. After washing, the section was reincubated with peroxidase conjugated swine anti-rabbit IgG (DAKO, Copenhagen) diluted 1:75 in PBS containing 10\% (v/v) mouse serum. The specimens were developed with $\mathrm{H}_{2} \mathrm{O}_{2}$ and 3-amino-9-ethyl carbazole and counterstained with haematoxylin.

\section{Enzyme-linked immunosorbent assay (ELISA)}

ELISAs were performed as antibody capture assays using affinity-purified rabbit anti-mFA1 as capture antibody. The plates were incubated overnight with test samples and calibrator (mouse amniotic fluid in twofold dilution series). Biotinylated affinity-purified rabbit anti-mFA1 was used as detector antibody and peroxidase-conjugated streptavidin, $\mathrm{H}_{2} \mathrm{O}_{2}$ and $\mathrm{O}$-phenylendiamine were used to develop the reaction.

\section{Results}

\section{Production of immunoreactants}

The sequence of purification of mouse FAI and the preparation of rabbit anti-mFAI antibodies is shown (Fig. 1). Before 


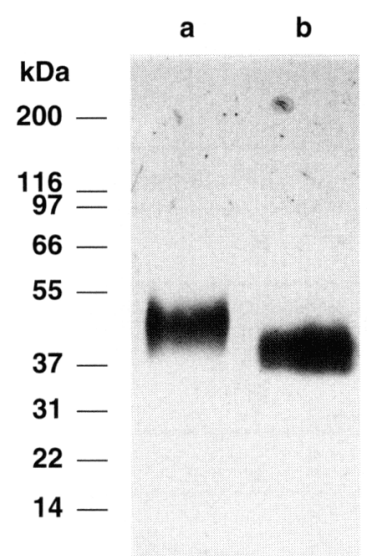

Fig. 2. Comparison of mouse fetal antigen I (mFA1) (lane a) with human FA1 (lane b) by SDS-PAGE under reducing conditions. The positions of the $M_{\mathrm{r}}$ markers are shown to the left. Both lanes were loaded with $0.9 \mu \mathrm{g}$ FA1 protein.

the generation of antibodies, FAI was identified by SDS-PAGE analysis as a characteristic broad, diffuse band similar to that seen for human FA1 (Jensen et al, 1993). In contrast to human FA1 (32-38 kDa), mouse FA1 protein migrated corresponding to an $M_{\mathrm{r}}$ of $42-50 \mathrm{kDa}$ (Fig. 2).

The final purification procedure for FAI (cation exchange chromatography followed by immunospecific affinity chromatography; Fig. 1) resulted in a recovery of $85 \%$ and a purity that allowed direct sequencing of the $39 \mathrm{~N}$-terminal amino acid residues.

The specificity of the ammonium sulfate-purified IgG fraction of the first generation antibodies was analysed in crossed immunoelectrophoresis (Fig. 3). The anti-mFA1 IgG met the criteria set for monospecificity.

The anti-mFAI antibodies showed pronounced crossreaction to rat FAI but no apparent crossreaction to human FAI when tested in ELISA with application of $2.5 \mu \mathrm{g}$ FA1. Analysis of mouse amniotic fluid and mouse serum in the hFAI ELISA showed no crossreaction $(<1 \%)$.

\section{$N$-terminal amino acid sequence}

The N-terminal sequence ( 39 residues) of the purified $\mathrm{mFA} 1$ showed a $74 \%$ identity to the $\mathrm{N}$-terminal sequence of human FAI (Jensen et al., 1993) and 100\% identity to the translated sequences of the cDNAs described as malk (Laborda et al., 1993), pref-1 (Smas and Sul, 1993) and SCP-1 (Maruyama et al., 1995) (Fig. 4).

\section{Immunohistochemistry}

One of the characteristic observations for hFAI is the localization of this antigen within the islets of Langerhans (Tornehave et al., 1993; Jensen et al., 1994). The anti-mFA1 antibodies were applied by an indirect immunoperoxidase technique on sections of pancreas from adult mice to verify that the localization of mFAI is similar to that of hFAI. A pronounced staining reaction of the endocrine tissue (islets of
Langerhans) was seen, whereas the exocrine tissue remained unstained (Fig. 5).

\section{Quantification of $m F A 1$ in serum}

Quantitative amino acid analysis of purified mFA1 and quantification in ELISA using mouse amniotic fluid (days 17-19 of pregnancy) as calibrator revealed a concentration of $25 \mu \mathrm{g}$ mFA1 $\mathrm{ml}^{-1}$ in amniotic fluid. The ELISA technique for quantification of mFAI using mouse amniotic fluid as calibrator had a detection threshold of $0.1 \mathrm{ng} \mathrm{ml}^{-1}$.

The normal serum concentration of 28 nonpregnant mice, age $>60$ days was $11.3 \mathrm{ng} \mathrm{ml}^{-1} \pm 5.0$ ( $\left.2 \mathrm{sD}\right)$. No significant difference was observed between male $(n=14)$ and female $(n=14)$ mice sera (unpaired $t$ test).

During pregnancy the serum concentrations did not rise above the normal nonpregnant values until 8-9 days before delivery, and the maximal concentration was reached 2 days prepartum (Fig. 6a). Postpartum, the serum concentration decreased rapidly to nonpregnant values within $12 \mathrm{~h}$. In one mouse (Fig. 6a), the exact time of birth was recorded and a tenfold decrease in the serum mFAI $3 \mathrm{~h}$ postpartum was observed.

In contrast to the rapid decrease of mFAI postpartum in adult mice, a much slower decrease was seen in newborn mice (Fig. 6b). The normal range (11.3 $\pm 5.0 \mathrm{ng} \mathrm{ml}^{-1}$ ) was not reached until the age of $>50$ days.

The fetal serum concentration of mFAI at day 16-19 was 1400 times that of the normal nonpregnant range and similar to that seen in amniotic fluid $\left(25 \mu \mathrm{g} \mathrm{m}{ }^{-1}\right)$. The correlation between the maternal serum concentration of mFAl (day 17-19 of pregnancy) and the number of fetuses at the same time is shown (Fig. 6c).

\section{Discussion}

The isolation and characterization of the mouse homologue to human FAI which is a new member of the epidermal growth factor superfamily (Jensen et al., 1993, 1994) is described. After a physicochemical purification procedure related to that applied for hFA1, the purified MFAI showed a broad band upon SDS-PAGE analysis. The purified mFA1 was used for generation of monospecific antibodies which made more efficient purification procedures possible and allowed further characterization of mFA1.

The N-terminal amino acid sequence (39 residues) revealed $74 \%$ identity to the corresponding amino acid sequence of hFAI. Human FAI is the processed and secreted gene product of the cDNA referred to as 'adrenal specific mRNA pG2' and human $d l k$, both of which have been isolated in the context of neuroendocrine tumours (Helman et al., 1990; Jensen, 1992; Jensen et al., 1993; Laborda et al., 1993). The amino acid sequence of mFAI could be aligned to a translated cDNA sequence of mouse dlk and SCP-1 from a mouse stromal cell line (Maruyama et al., 1995) with 100\% identity. Recently, Smas and Sul (1993) isolated a cDNA (pref-1) from mouse preadipocytes (3T3-L1) and their results indicated that the gene product of pref- 1 was involved in the differentiation of preadipocytes to adipocytes. Like dlk and SCP-I, the translated 

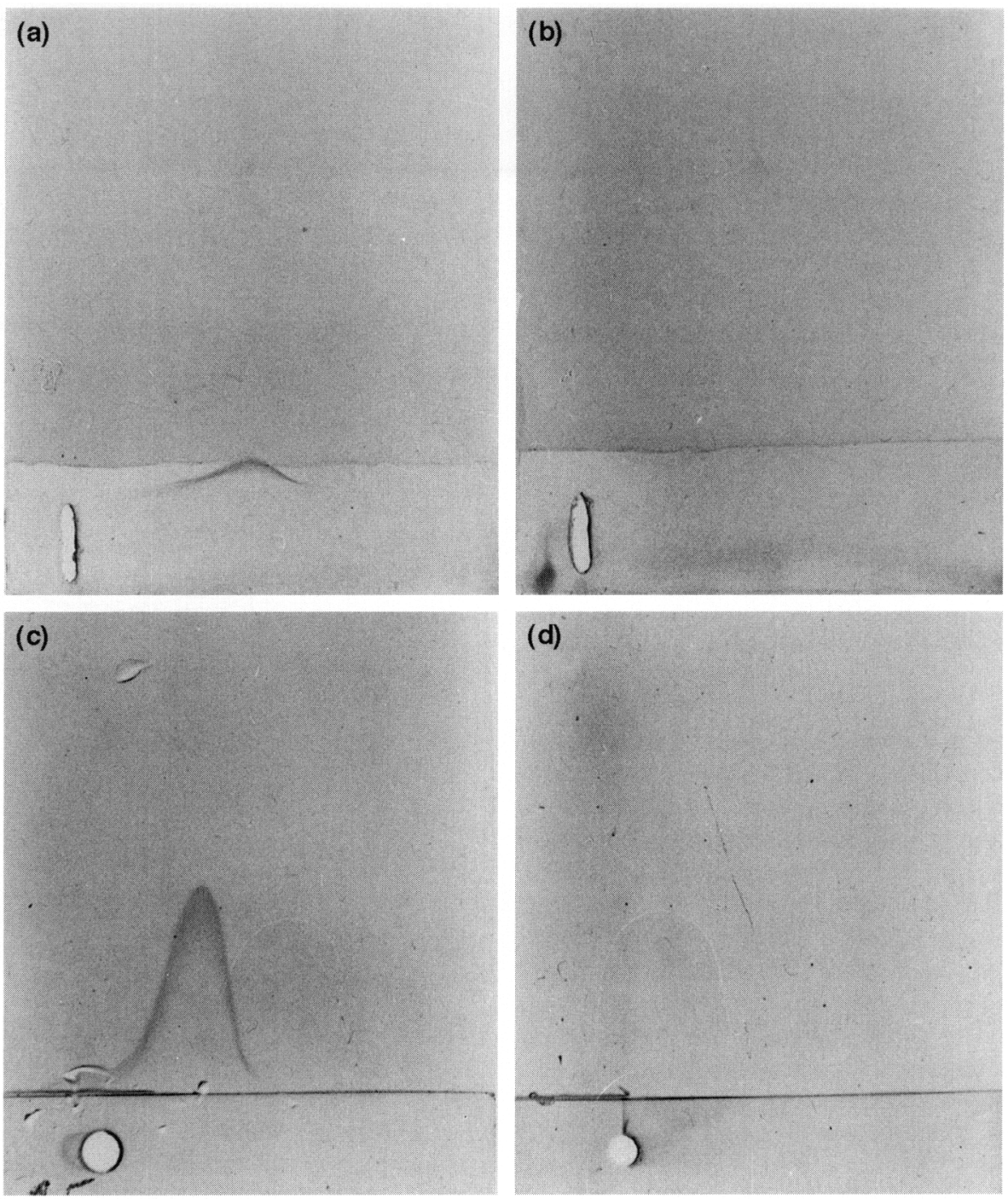

Fig. 3. Crossed immunoelectrophoretic analysis of the rabbit anti-mouse fetal antigen 1 (mFA1) antiserum after absorption with serum from nonpregnant adult mice. The wells of the first dimensional electrophoresis received $15 \mu \mathrm{lmAF}$ ( $a$ and $c$ ) or $15 \mu \mathrm{l}$ normal mouse serum ( $b$ and $d$ ). The second dimensional gels contained $50 \mu \mathrm{lgG} \mathrm{cm}-2$ agarose $\left(a\right.$ and $b$ ) or $10 \mu \mathrm{lgG} \mathrm{cm}^{-2}$ (c and d).

\section{Mouse FA1}

AECDPPCDPQYGFCEADNVCRCHVGFEGPLCDKCVTAPG . Mouse dlk/SCP-1/pref-1 $\cdots$ leader * AECDPPCDPQYGFCEADNVCRCHVGWEGPLCDKCVTAPG $\cdots \quad 100 \%$ Human FA1 AECFPACNPQNGFCEDDNVCRCQPGFQGPLCDQCVTSPG -

Fig. 4. N-terminal sequence ( 39 residues) of purified mouse fetal antigen 1 (mFA1) aligned to human FAI (Jensen et al., 1993) and the translated cDNA sequences of dlk (Laborda et al., 1993), pref-1 (Smas and Sul, 1993) and SCP-1 (Maruyama et al, 1993).

sequence of pref- 1 revealed $100 \%$ identity to the $\mathrm{N}$-terminal amino acid sequence of mFA1. These data suggest that mFAI is the processed, secreted gene product of mdlk, which in turn is identical to pref-1 and SCP-1, and the protein isolated from mouse amniotic fluid is the mouse homologue to human FA1. The homology to human FAI was further substantiated by the results of the immunohistochemical analysis of mFA1 in the pancreas, where the staining reaction was restricted to the endocrine cells of the islets of Langerhans, similar to the staining pattern observed for hFAI on adult human pancreas (Jensen et al., 1993). Moreover, positive immunostaining was observed in the adrenal and pituitary glands of adult mice (results not shown) in agreement with our findings on hFAI (Jensen et al., 1993, 1994; Larsen et al., 1996).

The general biology of FA1 remains to be elucidated but the extensive tissue distribution in the fetus and the more restricted tissue distribution in adults, together with the observed presence in certain cell lines, clearly points to involvement in 


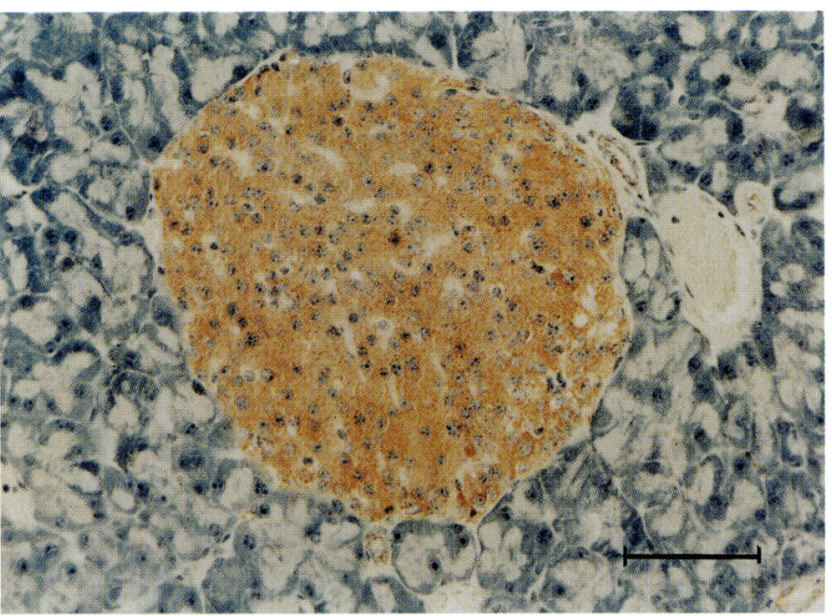

Fig. 5. Immunohistochemical analysis of mouse fetal antigen I (mFAI) in the pancreas from an adult mouse using rabbit anti-mFA1 IgG obtained by ammonium sulfate precipitation of absorbed rabbit anti-mFA1 anti-serum. Scale bar represents $40 \mu \mathrm{m}$.

differentiation. The secreted cleaved form of mFA1 is the most obvious source to exert this effect and human FA1 has been shown to be a heterogeneous glycoprotein with a molecular mass of $32-38 \mathrm{kDa}$; the heterogeneity is a result of a ragged C-terminal part of the molecule and glycosylation (Jensen et al., 1994). A similar broad band observed in SDS-PAGE analysis of mFA1 $(42-50 \mathrm{kDa})$ suggests that a similar post-translational modification of mFAI takes place. The difference in size between the two molecules could be due to differences in glycosylation, position of C-terminal truncation, unfolding of the compact molecule upon reduction in SDS-PAGE analysis or to a difference in amino acid sequence.

The $39 \mathrm{~N}$-terminal amino acids of mFA1 revealed $74 \%$ identity to hFA1 but a $<1 \%$ immunological crossreaction was produced when hFAI was applied to the MFAI ELISA and vice versa. This apparent lack of crossreactivity is most likely due to shared epitopes between rabbit, human and mouse FAI resulting in the rabbit recognizing those epitopes as 'self. Only epitopes that are different in human and mice and not shared by the rabbit can result in crossreactive immunoresponse.

Application of the ELISA technique on serum from nonpregnant adult mice revealed a normal range for mFAI of $11.3 \mathrm{ng} \mathrm{ml}{ }^{-1} \pm 5.0(2 \mathrm{sD})$. The most likely sources for this circulating pool of mFAI are the adrenal and pituitary glands, and the endocrine cells of the pancreas. However, in the fetal compartment (the mouse amniotic fluid and fetal serum) the concentration of mFAI was around 1400 times greater than the concentration seen in adult mouse serum, a difference similar to the 1000-fold difference observed between hFA1 in second trimester fluid and normal human serum (Jensen, 1992). During pregnancy the maternal serum concentration of mFA1 increased after mid-pregnancy to a serum concentration around 30 -fold greater than that seen in nonpregnant mice. The increased concentration of mFAI during pregnancy probably originates from the abundant fetal synthesis and secretion of mFA1. This hypothesis is supported by the positive correlation between maternal serum concentration and the number of fetuses. After delivery mFAI is cleared very rapidly from the (a)

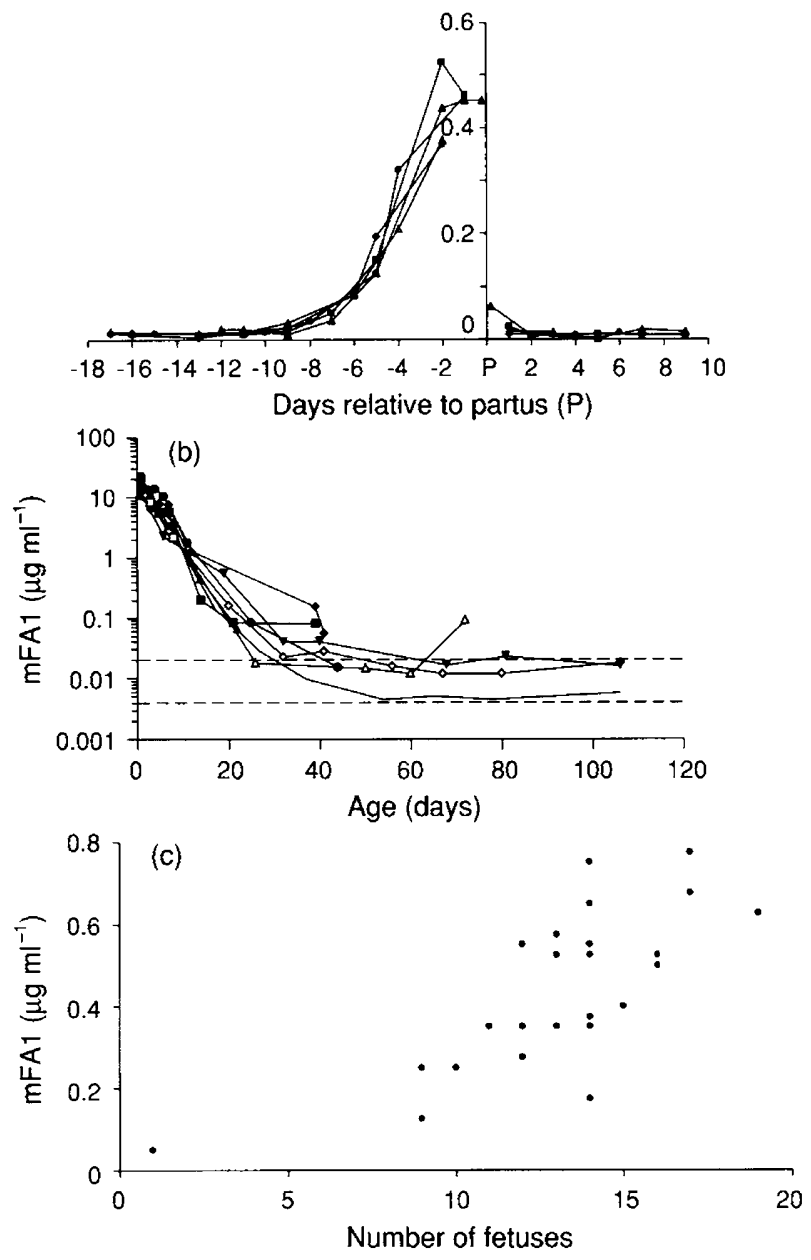

Fig. 6. The concentration of mouse fetal antigen $I$ (mFA1) measured by ELISA. (a) Serum concentration during and after pregnancy. (b) Serum concentration of $\mathrm{mFAI}$ in relation to age (days) of mice. Area between dotted lines indicates normal range $\left(11.3 \pm 5.0 \mu \mathrm{g} \mathrm{ml}^{-1}\right)$ for mFA1 in adult mouse serum. (c) Maternal serum concentrations at day 18 of gestation in relation to the number of fetuses.

maternal circulation and in one mouse where the exact time of delivery was recorded we observed a tenfold decrease in mFA1 concentration within $3 \mathrm{~h}$, indicating a disappearance rate with a $t_{1 / 2}<1 \mathrm{~h}$. By contrast, the decrease in serum mFAI in newborn mice was slow and normal adult amounts were not reached until the mice were $>50$ days old, suggesting an ongoing role of $\mathrm{mFA1}$ in growth and differentiation.

The extensive distribution of FAI in the fetus, the presence of mRNA encoding hFAI in neuroendocrine tumours of the lung (Laborda et al., 1993), and the identification of FA1 in the cytoplasm of small cell lung carcinoma and carcinoid tumours (Jensen ef al., 1994) suggest a role of FA1 in regulation of cell differentiation and growth. The presence of FA1 in the adrenal gland (Jensen et al., 1993), pheochromocytoma (Helman et al., 1990), in the pituitary gland and hormone-producing adenomas (Larsen et al., 1996), suggests that FA1 synthesis is secondary to a signal from cells of a neural origin or cells with neuroendocrine potential (Jensen et al., 1993). Moreover, the 
extensive distribution of hFAI in the glandular cells of fetal pancreas compared with adult pancreas, where hFAI is restricted to the islets of Langerhans, associates hFAI with the development of the endocrine structures of pancreas (Jensen et al., 1993, 1994; Tornehave et al., 1993).

This possible role of FAI in differentiation and growth is further substantiated by the similarity between FAI and the Notch and Delta proteins in Drosophila and their mammalian homologues. Notch and Delta proteins are involved in the differentiation of embryonic ectoderm into neural and epidermal structures (Campos-Ortega, 1993; Artavanis-Tsakonas et al., 1995). Ligands for Notch proteins, like Delta and Serrate, contain a characteristic DSL (Delta-Serrate-Lag 2) motif (Tax et al., 1994). Although FAI bears a close similarity to the Delta protein, this motif is absent from the FAI amino acid sequence (Jensen et al., 1994), which makes it unlikely that FAI is a ligand for mammalian Notch homologues.

In conclusion, the present work describes a mouse model for further studies of the biological significance of FAI and demonstrates that mFA1 is the processed secreted gene product of malk (Laborda et al., 1993), pref-1 (Smas and Sul, 1993) and SCP-1 (Maruyama et al., 1995).

The authors thank J. Brandt and A. Kliem for expert technical assistance. This work was supported by The Carlsberg Foundation, The Novo Nordic Foundation, The Foundation for Advancement of Medical Science, The Danish Medical Research Council and Direktør Civ.ing. Aage Louis Hansens Memorial Foundation.

\section{References}

Artavanis-Tsakonas S, Matsuno K and Fortini ME (1995) Notch signaling Science 268 225-232

Campos-Ortega JA (1993) Mechanisms of early neurogenesis in Drosophila melangaster Journal of Neurobiology 24 1307-1327

Fay TN, Jacobs I, Teisner B, Poulsen O, Chapman M, Stabile I, Bohn, H, Westergaard JG and Grudzinskas JG (1988) Two fetal antigens (FAI and FA2) and endometrial proteins (PP12 and PP14) isolated from amniotic fluid: characterization and distribution in fetal and maternal tissues European Journal of Obstetrics and Gynecology and Reproductive Biology 29 73-85
Folkersen J, Teisner B, Hinderson P and Svehag S-E (1980) A method for preparation of immunosorbent by direct coupling of dissociated immune complexes Joumal of Immunological Methods 32 327-338

Harboe N and Ingild A (1973) A Mamual of Quantitative Immunoelectrophoresis Ed. by Axelsen NH, Krøll J and Weeke B Scandinavian Journal of Immunology 2 (Supplementum 1) 161-164

Helman LJ, Sack LJ, Plon SE and Israel MA (1990) The sequence of an adrenal specific human cDNA, pG2 Nucleic Acid Research 3685

Jensen CH (1992) Human fetal antigen 1 (FA1): a Protein-Chemical Molecular Biological and Biological Characterization MScThesis, Odense University

Jensen CH, Teisner B, Højrup P, Rasmussen HB, Madsen OD, Nielsen B and Skjoedt K (1993) Studies on the isolation, structural analysis and tissue localization of fetal antigen 1 and its relation to a human adrenal specific cDNA, pG2 Human Reproduction 8 635-641

Jensen CH, Krogh TN, Højrup P, Clausen PP, Skjoedt K, Larsson L-I, Enghild J and Teisner B (1994) Protein structure of fetal antigen 1 (FA1). A novel circulating human epidermal-growth-factor-like protein expressed in neuroendocrine tumours and its relation to the gene products of dlk and pG2 European Journal of Biochemistry $22583-92$

Laborda J, Sausville EA, Hoffman T and Notario V (1993) dlk, a putative mammalian homeotic gene differentially expressed in small cell lung carcinoma and neuroendocrine tumour cell line Journal of Biological Chemistry 268 3817-3820

Larsen JB, Jensen CH, Schroder HD, Teisner B, Bjerre P and Hagen C (1996) Fetal antigen 1 and growth hormone in pituitary somatotroph cells The Lancet 347191

Maruyama K, Nishijima S, Kuromitsu S, Ichikawa A, Masuda E, Takemoto T, Kodama H and Kawashima H (1993) GenBank Seq ID g391760

Palomino M, Jensen CH, Teisner B, Nogales F, Brown C and Grudzinskas JG (1992) Immunohistochemical localization of fetal antigen 1 (FA1) in the human yolk sac and embryo Prenatal Diagnosis 12 (Supplement) 128

Smas CM and Sul HS (1993) Pref-1, a protein containing EGF-like repeats, inhibits adipocyte differentiation Cell 73 725-734

Tax FE, Yeargers JJ and Thomas JH (1994) Sequence of $C$. elegans lag-2 reveals a cell-signalling domain shared with Delta and Serrate of Drosophila Nature 368 150-154

Tornehave D, Fay TN, Teisner B, Chemnitz J, Westergaard JG and Grudzinkas JG (1989) Two fetal antigens (FA1 and FA2) and endometrial proteins (PP12 and PP14) isolated from amniotic fluid: localization in the fetus and adult female genital tract European Journal of Obstetrics and Gynecology and Reproductive Biology $30221-232$

Tornehave D, Jansen P, Teisner B, Rasmussen HB, Chemnitz J and Moscoso G (1993) Fetal antigen I (FAI) in the human pancreas: cell type expression, topological and quantitative variations during development Anatomy and Embryology $187 \quad 335-341$ 